\title{
Study on Hydrodynamic Characteristics of Fluted Floating Garbage Collection Device
}

ISSN: 2576-8840

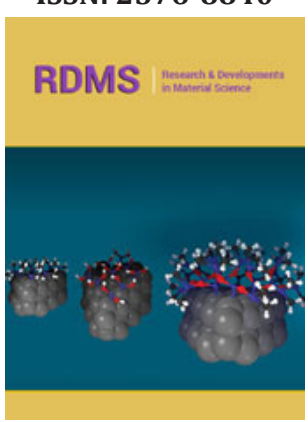

*Corresponding author: Zhou Ting, Department of Hydraulic Engineering, Tongji University, China

Submission: 䧳 February 25, 2020

Published: 制March 02, 2020

Volume 13 - Issue 1

How to cite this article: Zhou Ting, Nianqing Zhou, Simin Jiang. Study on Hydrodynamic Characteristics of Fluted Floating Garbage Collection Device. Res Dev Material Sci. 13(1).RDMS.000801.2020.

DOI: 10.31031/RDMS.2020.13.000801

Copyright@ Zhou Ting, This article is distributed under the terms of the Creative Commons Attribution 4.0 International License, which permits unrestricted use and redistribution provided that the original author and source are credited.

\author{
Zhou Ting ${ }^{1,2 *}$, Nianqing Zhou ${ }^{1}$ and Simin Jiang ${ }^{1}$ \\ ${ }^{1}$ Department of Hydraulic Engineering, Tongji University, China \\ ${ }^{2}$ Engineering, Nagoya Institute of Technology, Japan
}

\begin{abstract}
Water environmental pollution caused by floating garbage in rivers is increasingly worse, and severely affects biodiversity, human health and ecosystems. According to the hydrodynamic characteristics, the riverbank structure can be set up reasonably, which can solve the problem of floating garbage with energy saving and high efficiency. Change the length of concave part and guide wall to explore the hydrodynamic characteristics. The specific state of water flow is obtained by piv experiment, and the collection rate under different working conditions is obtained by floating garbage simulation experiment. The relationship between the collection effect and the device setting is analyzed. Finally, the numerical simulation is carried out by using Iric software, and the hydrodynamic motion is deeply analyzed. Through the comparative analysis of the results, it is found that with the increase of concave length and guide wall length, the collection rate increases obviously. This has a strong guiding significance for setting up the collection device.
\end{abstract}

Keywords: Hydrodynamic characteristics; Floating garbage; Collecting device; Simulation; Experiment

\section{Introduction}

In recent years, a large number of floating garbage carried by rivers have entered the ocean through estuaries, causing marine pollution as well as ecological and environmental problems. Many marine garbage is transported through waterbodies. Therefore, in order to reduce the amount of garbage entering the ocean, we need to pay attention to the collection and disposal of garbage into the sea channel, among which floating waste disposal is an urgent problem to be solved. The collection device designed in this paper can automatically collect garbage without adding external driving force [1]. The retaining plate in the device is used to change the flow state, and the flow is guided to drive the floating waste into the groove structure, so as to achieve the collection effect.

\section{Experimental Program}

The rectangular cross-section waterway with a length of $12 \mathrm{~m}$ and a wide $60 \mathrm{~cm}$ is used in the test model, and the gradient of the waterway is I = 1/1000. A PVC board with a width of $30 \mathrm{~cm}$ and a height of $3 \mathrm{~cm}$ is set on the left bank of the waterway, and the width of the main waterway is $30 \mathrm{~cm}$ [2]. As shown in Figure 1, the recess is set at an upstream position of $3 \mathrm{~m}$. In addition, a capture metal mesh of length $30 \mathrm{~cm}$ is also arranged downstream of the concave. The water depth is adjusted to $6 \mathrm{~cm}$ at the downstream end.

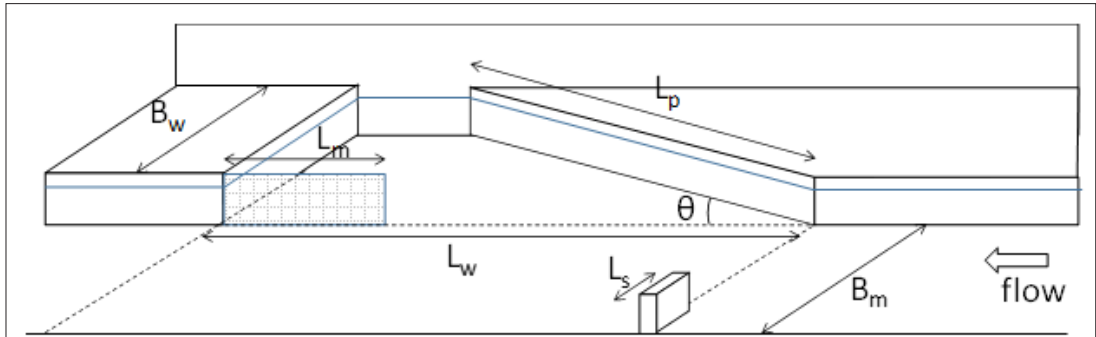

Figure 1: Schematic diagram of floating garbage automatic collection device. 
In order to show the change of surface flow direction more intuitively. Using talc powder as display agent, it is convenient to carry out visual flow velocity measurement by PIV (Particle Image Velocimetry) method. Take pictures with a digital camera at $1280 \times 780$ pixels and 30fps. The hydrodynamic conditions are described in Table 1. And the case setting as Table 2.

Table 1: Somatic diseases and concomitant OMD.

\begin{tabular}{|c|c|c|c|c|c|}
\hline $\begin{array}{c}\text { Discharge } \\
\mathbf{Q}(\mathbf{L} / \mathbf{s})\end{array}$ & $\begin{array}{c}\text { Water } \\
\text { Depth } \mathbf{h}(\mathbf{c m})\end{array}$ & $\begin{array}{c}\text { Mean Velocity } \\
\mathbf{U}_{\mathrm{m}}(\mathbf{c m} / \mathbf{s})\end{array}$ & Reynolds Number Re & $\begin{array}{c}\text { Froude } \\
\text { Number } \\
\text { Fr }\end{array}$ & $\begin{array}{c}\text { Bed Slope } \\
\mathbf{I}\end{array}$ \\
\hline 1.0 & 6.0 & 11.1 & 3300 & 0.41 & $1 / 1000$ \\
\hline
\end{tabular}

Table 2: Somatic diseases and concomitant OMD.

\begin{tabular}{|c|c|c|c|c|c|c|}
\hline Case & $\mathbf{B}_{\mathbf{m}} \mathbf{( c m )}$ & $\mathbf{B}_{\mathbf{w}}(\mathbf{c m})$ & $\mathbf{L}_{\mathbf{m}} \mathbf{( c m )}$ & $\mathbf{L}_{\mathbf{s}}(\mathbf{c m})$ & $\mathbf{L}_{\mathbf{w}}(\mathbf{c m})$ & $\mathbf{L}_{\mathbf{p}}(\mathbf{c m})$ \\
\hline C-96-30 & 30 & 15 & 40 & 10 & 96 \\
\hline C-96-60 & 30 & 15 & 40 & 10 & 96 & 60 \\
\hline C-120-30 & 30 & 15 & 40 & 10 & 120 \\
\hline C-120-60 & 30 & 15 & 40 & 10 & 120 \\
\hline
\end{tabular}

\section{Results and Discussion}

When setting up the test device, design with reference to the simulation results. In this laboratory test study, the two schemes of groove length of $0.96 \mathrm{~m}$ and $1.2 \mathrm{~m}$ were adopted. First, the length of the inner wall was controlled at $30 \mathrm{~cm}$ for the experiment. The collection rates of $0.96 \mathrm{~m}$ and $1.2 \mathrm{~m}$ were $42.55 \%$ and $46.475 \%$. Then, the length of the inner wall is controlled to the length of the $60 \mathrm{~cm}$ for the same experiment [3]. The results show that the collection rate of $0.96 \mathrm{~m}$ and $1.2 \mathrm{~m}$ is $46.35 \%$ and $50.475 \%$ respectively. The comparison of garbage collection rates between the two scenarios is shown in Figure 2.

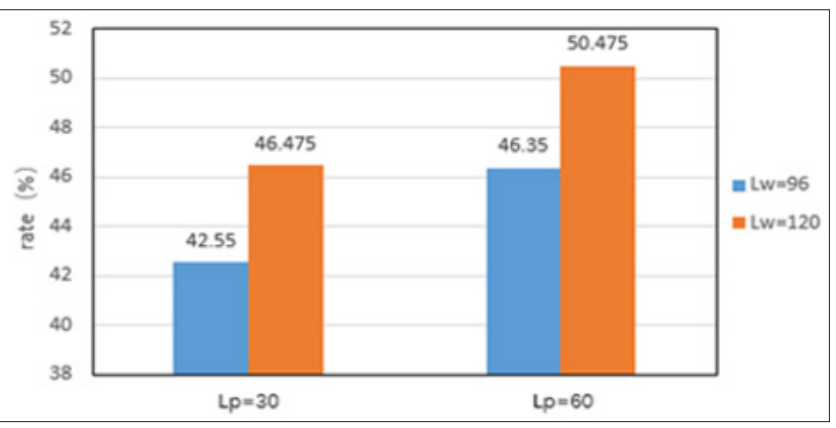

Figure 2: The garbage collection rate comparison chart.

The model with the best collection rate is $\mathrm{C}-120-60$, and its flow state is the focus of our attention. Figure 3 shows the flow chart obtained by processing the PIV experimental results. The velocity vector diagram of Figure 4 is obtained by numerical simulation with iric software, which is in good agreement with the experimental results.

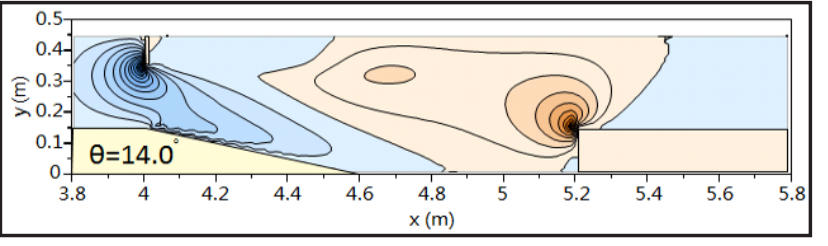

Figure 3: Streamline chart of PIV case C-120-60.

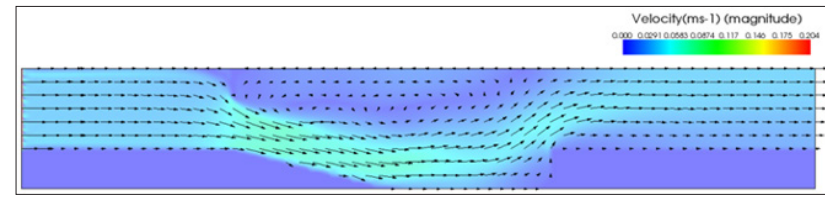

Figure 4: Velocity vector simulation of case C-12060.

It can be seen that the collection structure has a great influence on the surface turbulence. At the entrance of the device, due to the small cross section, the flow velocity increases sharply [4], and is acted by the guiding wall, and most of the flow flows to the recess collecting tank. A small portion of the water flows out of the main channel.

\section{Conclusion}

In this study, in order to collect floating waste in the river, the appropriate size ratio of the test model is determined by numerical simulation method, and then the specific collection results are obtained according to the laboratory test research, and the test results are analyzed and compared. Through a series of experimental studies, the following main conclusions are drawn: 
1) The flow direction can be adjusted by the river structure, and the floating garbage can be collected effectively by using the device designed by the riparian groove and baffle.

2) With the increase of the length of the inner wall of the device and the decrease of the angle of the inner wall, the capture rate shows an upward trend.

\section{References}

1. Tominaga A, Horibe F, Sakaki T (2012) Restraining effects of sand deposition by shielding of entrance in an artificial embayment. Journal of Japan Society of Civil Engineers 67(4): 1057-1062.
2. Jong J, Tominaga A (2012) Flow structure and sedimentation mechanism in the riverside embayment with various shape configuration. Journal of Japan Society of Civil Engineers 67(4): 1051-1056.

3. Chi-Wai NG, Shu L, Xiaoxuan LU (2018) A plastic tide: mining floating plastic waste through landscape processes. Landscape Architecture Frontiers 6(4): 126-135.

4. Vukić M, Institut KS, Beograd, Spruk U, Aluxom (2009) Vessels and floating boats waste water pollution monitoring system. Agricultural Engineering 2009(8): 62.

For possible submissions Click below: 